\title{
Penggunaan VCD dan Leaflet untuk Peningkatan Pengetahuan, Sikap, dan Perilaku Siswa dalam Pencegahan Kecelakaan Sepeda Motor
}

\author{
Visual Compact Disks and Leaflet Usage to Increase the Knowledge, \\ Attitude and Behavior of Students in Motorcycle Accident Prevention
}

\author{
Mulyono Notosiswoyo
}

Pusat Teknologi Intervensi Kesehatan Masyarakat Badan Penelitian dan Pengembangan Kesehatan Kementerian Kesehatan RI

\begin{abstract}
Abstrak
Indonesia belum mempunyai kebijakan penyuluhan pencegahan kecelakaan sepeda motor yang efektif. Tujuan penelitian ini adalah menilai efektivitas penggunaan visual compact disk (VCD) dan leaflet terhadap peningkatan pengetahuan, sikap dan perilaku siswa SLTA dalam pencegahan kecelakaan sepeda motor di Kota Bekasi pada tahun 2010. Desain penelitian yang digunakan quasi experiment dengan rancangan equivalent pretest and post-test with control group, dengan intervensi pemutaran VCD dan pemberian leaflet. Sampel dihitung berdasarkan uji 2 proporsi, diperoleh sampel minimal 211 untuk yang di intervensi dan 211 untuk kontrol. Mereka diambil dari siswa SLTA kelas I dan kelas II yang sering mengendarai sepeda motor. Evaluasi hasil intervensi dilakukan setelah tiga bulan. Alat pengumpul data adalah kuesioner yang telah diuji coba. Analisis data menggunakan uji Kolmogorov-Smirnov, uji-t berpasangan dan uji-t independen. Hasil penelitian menunjukan uji-t berpasangan pada kelompok yang di intervensi meningkatkan rerata skor pengetahuan, sikap, dan perilaku siswa SLTA sebelum dibandingkan sesudah pemutaran VCD dan pemberian leaflet bermakna (nilai $p<0,05$ ), tetapi pada kelompok kontrol hanya terjadi peningkatan rerata skor perilaku sebelum dibandingkan sesudah adanya perlakukan. Sedangkan, hasil uji-t independen menunjukan hanya pada rerata skor variabel pengetahuan terdapat perbedaan peningkatan skor antara kelompok intervensi dan kelompok kontrol yang bermakna (nilai $p<0,05$ ). Kesimpulannya, penyuluhan menggunakan VCD dan leaflet dapat meningkatkan pengetahuan siswa SLTA dalam pencegahan kecelakaan sepeda motor.
\end{abstract}

Kata kunci: Kecelakaan lalu lintas, leaflet, pencegahan, VCD

\section{Abstract}

Indonesia does not have a policy of promotion motorcycle accident prevention. The purpose of this study was to assess the effectiveness of the Visual Compact Disks and leaflets to increase in knowledge, attitudes and behavior of the motorcycle accident prevention on high school students in
Bekasi City. The method used a non-randomized quasi experimental pretest and post-test control group design. Samples are high school students as a intervention group and vocational high school students as a control group in Bekasi in 2010. Three months after the intervention, conducted an evaluation to assess the increasing of knowledge, attitudes and behavior of a motorcycle accident prevention. Data collection was a questionnaire that was tested. Analysis of the data using the Kolmogorov-Smirnov test, paired $\mathrm{t}$-test and independent t-test. The result of the study shows that the paired t-test in the intervention group mean scores improve knowledge, attitudes and behavior of high school students before than after playback of VCDs and leaflets giving significant ( $p$ value $<0.05$ ), but in the control group only increased the mean behavior scores before than after the introduction of treatment. While the results of the independent t-test showed only the mean score difference variable increase in knowledge scores between the groups in the intervention and control groups were significant ( $p$ value< 0.05 ). To conclude, extension using VCD and leaflets can improve high school students' knowledge in the prevention of a motorbike accident.

Keywords: Traffic accidents, leaflet, prevention, VCD

\section{Pendahuluan}

Kecelakaan lalu lintas adalah suatu peristiwa di jalan yang tidak diduga dan tidak disengaja, yang melibatkan kendaraan dengan atau tanpa pengguna jalan lain yang mengakibatkan korban manusia dan atau kerugian harta benda. ${ }^{1}$ Kejadian kecelakaan lalu lintas dari tahun ke tahun mengalami peningkatan dengan kerugian yang sangat besar, baik materiil maupun nonmateriil. ${ }^{2}$ Korban kecelakaan lalu lintas sebagian besar laki-laki dengan

Alamat Korespondensi: Mulyono Notosiswoyo, Pusat Teknologi Intervensi Kesehatan Masyarakat Balitbangkes Kemenkes RI, Jl. Percetakan Negara No. 29 Jakarta Pusat, Hp.08128209155,e-mail: mulyono_babel@yahoo.co.id 
usia 15 - 40 tahun. Para korban kecelakaan lalu lintas 90\% mengalami cacat seumur hidup (disability adjustment life years/ DALYs). ${ }^{3}$ Untuk mencegah kecelakaan lalu lintas, khususnya sepeda motor, perlu adanya upaya pencegahan, antara lain melalui penyuluhan atau intervensi. Upaya penyuluhan untuk mengubah pengetahuan, sikap, dan perilaku akan lebih efektif dilakukan terhadap kelompok umur remaja (SLA) daripada dilakukan pada kelompok umur dewasa. Hal tersebut sesuai dengan hasil penelitian yang sejenis yaitu tentang perilaku masyarakat berkaitan dengan pengobatan sendiri, pengetahuan, sikap, dan perilakunya dapat ditingkatkan melalui penyuluhan kesehatan. ${ }^{4}$ Upaya penyuluhan tersebut dilakukan dengan menggunakan media sebagai alat bantu yang dapat menarik perhatian sasaran.

Menurut Colletti dalam Soekartawi, ${ }^{5}$ urutan efektivitas penggunaan media pengajaran dalam kaitannya dengan daya serap siswa menangkap informasi, media pengajaran dengan VCD merupakan media audio visual yang paling efektif. Dengan demikian, betapa pentingnya penggunaan media pengajaran/penyuluhan VCD yang dapat dilihat langsung oleh siswa sehingga mempunyai pengalaman belajar yang mendekati konkret.

Beberapa keuntungan yang didapat jika bahan ajar/ penyuluhan yang disajikan dalam bentuk video/film, antara lain memudahkan seseorang belajar sendiri, dapat menyajikan situasi yang kompetitif, dapat diulang-ulang, dapat menampilkan sesuatu yang detail dari benda yang bergerak kompleks yang sulit dilihat dengan mata, dapat dipercepat maupun diperlambat, dapat diulang pada bagian tertentu yang perlu lebih jelas, dapat diperbesar, memungkinkan untuk membandingkan antara dua adegan berbeda yang diputar dalam waktu ber-samaan, dan dapat digunakan sebagai tampilan nyata dari suatu adegan, promosi suatu produk, wawancara, serta menampilkan suatu proses. ${ }^{6}$ Dalam penelitian ini, media yang digunakan adalah VCD dan leaflet, dengan asumsi bahwa media leaflet dapat membantu me-ningkatkan pengetahuan, sikap, dan perilaku pencegah-an kecelakaan sepeda motor pada sasaran. Hal tersebut sesuai dengan hasil penelitian IC Makie et $a l,{ }^{7}$ yang mengemukakan bahwa media leaflet dapat mengubah tindakan apoteker dalam penyediaan obat anak yang mengandung gula di apotek.

Dalam melakukan penyuluhan (intervensi) menggunakan VCD dan leaflet, dibutuhkan perencanaan penyuluhan yang mencakup masalah yang dihadapi masyarakatnya dan program yang ditunjang, sosial budaya, lokasi, transportasi serta komunikasi yang digunakan masyarakat; tujuan penyuluhan, apakah untuk melakukan perubahan pengetahuan, perubahan sikap, atau perubahan perilaku; siapa yang akan menjadi sasaran primer, sasaran sekunder dan sasaran tersier; pesan penyuluhan disesuaikan dengan masalah dan tujuan penyuluhan; metode penyuluhan disesuaikan dengan tujuan penyuluhan, kemampuan penyuluh, kemampuan dan jumlah sasaran, pesan yang akan disampaikan, waktu dan fasilitas lain yang tersedia; alat bantu penyuluhan yang disesuaikan dengan tujuan, pesan dan metode penyuluhan; tempat penyuluhan yang dikenal, mudah dicapai oleh sasaran, serta ruangan yang mempunyai pencahayaan, ventilasi, suhu dan tempat duduk yang sesuai; waktu penyuluhan disesuai dengan waktu luang sasaran dan tempat penyuluhan; pelaksana penyuluhan disesuaikan dengan pesan yang akan disampaikan, metode yang digunakan dan target sasaran; rencana evaluasi terhadap langkah-langkah penyuluhan maupun membandingkan hasil pe-nyuluhan dengan tujuan. ${ }^{8}$

Media VCD adalah bahan ajar yang merupakan kombinasi dari dua atau lebih media (audio, teks, grafik, gambar animasi, dan video) yang pengoperasiannya perlu alat untuk menayangkan seperti televisi atau layar LCD dan komputer. ${ }^{6}$ Dengan demikian, yang dimaksud dengan media VCD dalam penelitian ini adalah alat untuk menyampikan informasi pengajaran dalam bentuk video atau film terkait dengan pokok bahasan tentang pencegahan kecelakaan sepeda motor, nantinya siswa melakukan proses belajar mengajar dengan melihat pemutaran materi melalui VCD pada CD player atau layar televisi. Disamping menggunakan media VCD, siswa juga diberi leaflet. Leaflet atau lembar balik adalah selembar kertas yang dilipat sedemikian rupa, berisi tulisan dan gambar, yang tercetak berisi tentang suatu masalah khusus untuk sasaran dengan tujuan tertentu. ${ }^{9}$

Berdasarkan teori dan konsep-konsep tersebut, akan dilakukan intervensi atau penyuluhan dengan VCD dan leaflet untuk mencegah terjadinya kecelakaan lalu lintas sepeda motor. Diasumsikan bahwa sebagian besar siswa SLTA di Kota Bekasi menggunakan sepeda motor dan akhir-akhir ini banyak mengalami kecelakaan lalu lintas. Tujuan penelitian adalah menghasilkan VCD dan leaflet yang dapat digunakan sebagai sarana atau media pencegahan kecelakaan sepeda motor, dan menguji coba penyuluhan menggunakan VCD dan leaflet (materi dan metode) terhadap pengetahuan, sikap dan perilaku pengendara sepeda motor dalam pencegahan kecelakaan lalu lintas. Manfaat penelitian bagi para pengambil keputusan, diharapkan model intervensi (cara dan materi) yang dihasilkan dapat digunakan untuk menunjang program pencegahan kecelakaan sepeda motor, khususnya bagi siswa SLTA. Dengan demikian, diharapkan para siswa secara sadar (bukan karena takut polisi) dapat mematuhi peraturan lalu lintas sehingga kecelakaan lalu lintas sepeda motor dapat dicegah.

\section{Metode}

Desain penelitian yang digunakan adalah quasi experiment dengan rancangan equivalent pre-test and post- 
test with control group. Lokasi penelitian di Kota Bekasi, Jawa Barat, tahun 2010. Sampel penelitian diambil siswa SLTA kelas I dan II yang sering mengendarai sepeda motor di dua SLTA Negeri sebagai kelompok yang di intervensi dan dua SLTA Negeri sebagai kelompok kontrol. Jarak antara sekolah yang dijadikan kelompok intervensi dengan sekolah yang dijadikan kelompok kontrol letaknya berjauhan untuk mencegah terjadinya kontaminasi materi penyuluhan pencegahan kecelakaan sepeda motor. Waktu penelitian selama 10 bulan. Jumlah responden minimal yang didapatkan berdasarkan uji dua proporsi sebesar 211. Selanjutnya, untuk mengganti bila ada sampel yang drop-out maka sampel diambil 230 siswa yang diintervensi dan 230 siswa sebagai kontrol. Pengambilan sampel dilakukan secara proporsional berdasarkan catatan nama-nama siswa kelas I dan kelas II masing-masing sekolah. Selain data kuantitatif, dilakukan pengumpulan data sekunder untuk membuat VCD dan leaflet.

Sebelum kegiatan intervensi atau penyuluhan dilakukan pre-test dengan menggunakan kuesioner untuk mengetahui pengetahuan, sikap dan perilaku responden dalam pencegahan kecelakaan sepeda motor. Intervensi dilakukan dengan cara penyuluhan menggunakan media VCD dan responden diberi leaflet serta diberi VCD agar diputar di rumah atau tempat lain pada kesempatan lain. Petugas yang melakukan penyuluhan adalah peneliti dibantu oleh guru sekolah setempat dengan menggunakan bahasa Indonesia. Agar penyuluhan berjalan efektif, sasaran dibagi dalam tiga kelompok. Sebelum kegiatan tersebut dilakukan, konsultasi dengan pihakpihak yang terkait dilakukan. Sesudah kegiatan penyuluhan dilakukan evaluasi dengan menggunakan kuesioner untuk mengetahui pendapat sasaran terhadap konten VCD serta leaflet yang digunakan sebagai media penyuluhan. Tiga bulan kemudian dilakukan evaluasi/post test terhadap responden yang telah diberi penyuluhan dengan menggunakan kuesioner yang sama. Analisis data dilakukan dengan uji Kolmogorov-Smirnov, uji-t berpasangan, dan uji-t independen.

\section{Hasil}

Pada penelitian ini, telah dibuat VCD dengan isi/ materi tentang contoh berkendaraan sepeda motor tanpa perhitungan yang menyebabkan terjadinya kecelakaan lalu lintas dan contoh helm yang memenuhi standar SNI serta cara menggunakan helm yang baik dan benar; anjuran agar menggunakan helm yang berstandar SNI; syarat-syarat sepeda motor yang layak pakai yang meliputi ban tidak gundul, rem keduanya dalam keadaan baik/pakem, kaca spion terpasang dengan baik, semua lampu menyala, klakson dapat berbunyi dengan baik, kondisi rantai tidak kendor dan terpasang dengan baik, kondisi mesin dan body baik; cara mengendarai sepeda motor yang baik dan benar yang meliputi anjuran meng- hargai pejalan kaki dan penyebrang jalan dalam berkendara sepeda motor, anjuran tidak menyalip di tikungan, anjuran tidak menggunakan telepon genggam selama mengendarai sepeda motor, anjuran selalu memakai helm dalam bersepeda motor, anjuran tidak berkendaraan sepeda motor di trotoar jalan, anjuran untuk mengurangi kecepatan ketika jalan di tikungan, anjuran untuk mengenali rambu-rambu dan marka jalan; contoh kejadian kecelakaan sepeda motor yang terjadi akibat tidak mematuhi aturan lalu lintas.

Materi leaflet meliputi anjuran selalu menggunakan helm bila mengendarai sepeda motor dan memakainya dengan benar, serta motor yang dikendarainya agar selalu dalam keadaan layak jalan, tidak kurang alat kelengkapannya; himbauan agar tidak menggunakan trotoar dan jembatan penyeberangan sebagai tempat lalu lintas sepeda motor, tidak menggunakan telepon genggam saat mengendarai sepeda motor, selalu mengutamakan keselamatan dalam berlalu lintas, selalu mematuhi ramburambu lalu lintas dan marka jalan, bila mengantuk atau tidak konsentrasi jangan mengendarai sepeda motor, dan bila menyalip agar memperhatikan baik-baik kendaraan di sekitar kita. Leaflet dibuat dengan bahasa yang sederhana, menarik, dan mudah dipahami serta dengan warna yang menarik.

Jumlah sampel yang dapat diolah dihitung adalah 410. Mean skor variabel pengetahuan sebelum intervensi sebesar 22,91 dan sesudah intervensi sebesar 23,08. Mean skor variabel sikap sebelum intervensi sebesar 21,74 dan sesudah intervensi sebesar 21,91. Mean skor variabel perilaku sebelum intervensi sebesar 33,78 dan sesudah intervensi sebesar 35,59. Standar deviasi pengetahuan sebelum intervensi sebesar 1,36 dan sesudah intervensi sebesar 1,23. Standar deviasi sikap sebelum intervensi sebesar 1,491 dan sesudah intervensi sebesar 1,63. Standar deviasi perilaku sebelum intervensi sebesar 3,46 dan sesudah intervensi sebesar 3,421. Nilai Z pengetahuan sebelum intervensi sebesar 3,532 dan sesudah intervensi sebesar 3,517. Nilai $Z$ sikap sebelum intervensi sebesar 2,873 dan sesudah intervensi sebesar 2,975. Nilai Z perilaku sebelum intervensi sebesar 3,568 dan sesudah intervensi sebesar 4,140. Sedangkan, nilai p seluruh variabel sebesar 0,000 (nilai $p<0,05$ ) sehingga dapat dikatakan data terdistribusi normal, dapat dilakukan uji$\mathrm{t}$ berpasangan dan uji-t independen (Tabel 1).

Pada kelompok yang diintervensi, rerata skor pengetahuan sebelum intervensi 22,94 dan sesudah intervensi 23,26 , terdapat peningkatan sebesar 0,32 dengan nilai $p$ $=0,001$. Rerata skor sikap sebelum intervensi 21,65 dan sesudah intervensi 21,99 terdapat peningkatan sebesar 0,34 dengan nilai $\mathrm{p}=0,001$. Rerata skor perilaku sebelum intervensi 33,94 dan sesudah intervensi 35,82 terdapat peningkatan sebesar 0,88 dengan nilai $p=0,001$. Sedangkan pada kelompok kontrol rerata skor penge- 
Tabel 1. Uji Kolmogorov-Smirnov Normalitas Skor Pengetahuan, Sikap, dan Perilaku Siswa SLTA Sebelum dan Sesudah Intervensi

\begin{tabular}{|c|c|c|c|c|c|c|}
\hline \multirow{2}{*}{ Keterangan } & \multicolumn{2}{|c|}{ Pengetahuan } & \multicolumn{2}{|c|}{ Sikap } & \multicolumn{2}{|c|}{ Perilaku } \\
\hline & Sebelum & Sesudah & Sebelum & Sesudah & Sebelum & Sesudah \\
\hline $\mathrm{n}$ & 410 & 410 & 410 & 410 & 410 & 410 \\
\hline Mean & 22,91 & 23,08 & 21,74 & 21,91 & 33,78 & 35,59 \\
\hline SD & 1,36 & 1,23 & 1,49 & 1,63 & 3,46 & 3,42 \\
\hline Nilai Z & 3,532 & 3,517 & 2,873 & 2,975 & 3,568 & 4,140 \\
\hline Nilai $\mathrm{p}$ & 0,000 & 0,000 & 0,000 & 0,000 & 0,000 & 0,000 \\
\hline
\end{tabular}

Tabel 2. Hasil Uji-t Berpasangan, Rerata Skor Pengetahuan, Sikap, dan Perilaku Siswa SLTA Sebelum dan Sesudah Intervensi

\begin{tabular}{llccc}
\hline Kelompok & \multicolumn{1}{c}{ Variabel } & Sebelum & Sesudah & Nilai p \\
\hline \multirow{2}{*}{ Intervensi } & Rerata pengetahuan & 22,94 & 23,26 & 0,001 \\
& Rerata sikap & 21,65 & 21,99 & 0,001 \\
\multirow{3}{*}{ Kontrol } & Rerata perilaku & 33,94 & 35,82 & 0,001 \\
& Rerata pengetahuan & 22,88 & 22,89 & 0,935 \\
& Rerata sikap & 21,82 & 21,83 & 0,947 \\
& Rerata perilaku & 33,46 & 34,22 & 0,001 \\
\hline
\end{tabular}

Tabel 3. Hasil Uji-t Independen Pengaruh Pemutaran VCD dan Pemberian Leaflet terhadap Peningkatan Pengetahuan, Sikap, dan Perilaku Siswa SLTA

\begin{tabular}{llllll}
\hline \multirow{2}{*}{ Variabel } & \multicolumn{2}{l}{ Kelompok Intervensi } & \multicolumn{2}{l}{ Kelompok Kontrol } & \multirow{2}{*}{ Nilai p } \\
\cline { 2 - 4 } & Sebelum & Sesudah & Sebelum & Sesudah & \\
\hline Pengetahuan & 22,94 & 23,26 & 22,88 & 22,89 & 0,048 \\
Sikap & 21,65 & 21,99 & 21,82 & 21,83 & 0,065 \\
Perilaku & 33,94 & 35,82 & 33,46 & 34,22 & 0,729 \\
\hline
\end{tabular}

tahuan sebelum intervensi 22,88 dan sesudah intervensi 22,89 terdapat kenaikan sebesar 0,01 dengan nilai $\mathrm{p}=$ 0,935 . Rerata skor sikap sebelum intervensi 21,82 dan sesudah intervensi 21,83 terdapat kenaikan sebesar 0,01 dengan nilai $p=0,947$. Rerata skor perilaku sebelum intervensi 33,46 dan sesudah intervensi 34,22 terdapat kenaikan sebesar 0,76 dengan nilai $p=0,001$. Berdasarkan hal tersebut diatas dapat diambil kesimpulan hasil uji-t berpasangan pada kelompok intervensi meningkatkan rerata skor pengetahuan, sikap dan perilaku siswa SLTA sebelum dibandingkan sesudah pemutaran VCD dan pemberian leaflet bermakna (nilai $\mathrm{p}<0,05$ ), tetapi pada kelompok kontrol hanya terjadi peningkatan rerata skor perilaku sebelum dibandingkan sesudah adanya perlakuan (Tabel 2).

Peningkatan skor kelompok intervensi pada variabel pengetahuan sebesar 0,32, pada variabel sikap sebesar 0,34 , dan pada variabel perilaku sebesar 0,88 . Sedangkan, skor pada kelompok kontrol untuk variabel pengetahuan terdapat peningkatan sebesar 0,01, variabel sikap terjadi peningkatan sebesar 0,01 , dan peningkatan variabel perilaku sebesar 0,76. Berdasarkan data tersebut, hasil uji-t independen pada variabel pengetahuan, sikap, dan perilaku, menyatakan bahwa perbedaan peningkatan sikap dan perilaku antara kelompok intervensi dan kelompok kontrol tidak bermakna (nilai $\mathrm{p}>0,05$ ). Namun, pada variabel pengetahuan tentang pencegahan kecelakaan sepeda motor, terdapat perbedaan peningkatan antara kelompok intervensi dan kelompok kontrol sebesar 0,31 dengan nilai $p=0,048$ (nilai $p<0,05$ ). Dengan demikian, pemutaran VCD dan pemberian leaflet efektif dapat meningkatkan pengetahuan siswa SLTA dalam pencegahan kecelakaan sepeda motor (Tabel 3).

Sebagian besar $(76,5 \%)$ siswa empat SLTA di Kota Bekasi berpendapat bahwa isi VCD menarik dan komunikatif. Sedangkan yang berpendapat bahwa isi VCD tidak menarik dan tidak komunikatif hanya 9 orang atau $3,91 \%$. Besarnya persentase responden yang berpendapat bahwa VCD dapat meningkatkan sikap 198 orang atau $83,07 \%$ dan yang berpendapat bahwa VCD dapat meningkatkan perilaku pencegahan kecelakaan sepeda motor 211 orang atau 92,52\%. Dari hasil tersebut, menunjukkan bahwa VCD dapat dijadikan media komunikasi yang efektif dalam penyuluhan pencegahan kecelakaan lalu lintas sepeda motor (Tabel 4).

Sebagian besar $(62,59 \%)$ siswa SLTA yang diintervensi berpendapat bahwa isi leaflet menarik dan komunikatif. Sedangkan, yang berpendapat bahwa leaflet yang digunakan untuk intervensi tidak menarik dan tidak komunikatif hanya 15 siswa (6,52\%). Di samping itu, $88,26 \%$ responden berpendapat bahwa leaflet dapat meningkatkan sikap pencegahan kecelakaan sepeda motor. $90,44 \%$ berpendapat bahwa leaflet dapat meningkat perilaku pencegahan kecelakaan sepeda motor. Dengan demikian, leaflet merupakan sarana/media yang efektif untuk penyuluhan pecegahan kecelakaan sepeda motor karena sebagian besar responden menyatakan bahwa isi VCD dan leaflet dapat meningkatkan perilaku pencegahan kecelakaan sepeda motor, maka diharapkan mereka yang telah mendapatkan penyuluhan, perilaku pencegahan kecelakaan lalu lintasnya akan lebih baik (Tabel 5).

\section{Pembahasan}

Terdapat beberapa kelemahan dalam penelitian ini, meskipun peneliti telah berusaha untuk meminimalkan 
Tabel 4. Distribusi Frekuensi Pendapat Tentang Penggunaan VCD Sebagai Media Intervensi terhadap Siswa SLTA yang Diintervensi

\begin{tabular}{llll}
\hline Variabel & Kategori & $\mathbf{n}$ & $\%$ \\
\hline Isi VCD sebagai media penyuluhan & Menarik dan komunikatif & 172 & 76,5 \\
& Menarik tapi tidak komunikatif & 12 & 5,3 \\
& Komunikatif tapi tidak menarik & 37 & 16,19 \\
Isi VCD dapat meningkatkan sikap terhadap & Tidak menarik dan tidak komunikatif & 9 & 3,91 \\
pencegahan kecelakaan sepeda motor & Dapat & 198 & 83,07 \\
Isi VCD dapat meningkatkan perilaku & Tidak dapat & 32 & 16,93 \\
pencegahan kecelakaan sepeda motor & Dapat & 211 & 92,52 \\
\hline Jumlah & Tidak dapat & 19 & 7,48 \\
\hline
\end{tabular}

Tabel 5. Distribusi Frekuensi Pendapat Tentang Penggunaan Leaflet Sebagai Media Intervensi terhadap Siswa SLTA yang Diintervensi

\begin{tabular}{llll}
\hline Variabel & Kategori & n & $\%$ \\
\hline Isi leaflet sebagai media penyuluhan & Menarik dan komunikatif & 143 & 62,17 \\
& Menarik tapi tidak komunikatif & 42 & 18,26 \\
& Komunikatif tapi tidak menarik & 30 & 13,05 \\
Isi leaflet dapat meningkatkan sikap terhadap & Tidak menarik dan tidak komunikatif & 15 & 6,52 \\
pencegahan kecelakaan sepeda motor & Dapat & 203 & 88,26 \\
Isi leaflet dapat meningkatkan perilaku & Tidak dapat & 27 & 11,74 \\
pencegahan kecelakaan sepeda motor & Dapat & 208 & 90.44 \\
\hline Jumlah & Tidak dapat & 22 & 9,56 \\
\hline
\end{tabular}

hal tersebut. Pada penelitian ini, evaluasi hanya dilakukan dengan wawancara tidak dilakukan observasi sehingga tidak menutup kemungkinan responden tidak jujur dalam menjawab pertanyaan, lupa serta salah dalam menafsirkan pertanyaan. Di samping itu, tidak dilakukan pemantauan terhadap proses penyuluhan untuk mengetahui apakah penyuluhan berjalan efektif, serta tidak dilakukan wawancara mendalam untuk mengetahui pendapat sasaran terhadap proses dari penyuluhan tersebut, baik ditinjau dari petugasnya maupun tempatnya. Di samping itu, pelaksanaan penyuluhan dilakukan dengan membagi dalam tiga kelompok sehingga kemungkinan terjadi perbedaan tingkat efektivitas antara kelompok yang satu dengan kelompok yang lain.

Terjadi peningkatan skor rerata pengetahuan tentang pencegahan kecelakaan sepeda motor pada responden kelompok perlakuan secara bermakna tetapi tidak terjadi pada kelompok responden kontrol. Dengan demikian, penggunaan VCD dan leaflet sebagai media penyuluhan cukup efektif terutama untuk meningkatkan pengetahuan. Hasil penelitian tersebut diperkuat dengan hasil penelitian sejenis yang berjudul meningkatkan hasil belajar sejarah siswa melalui pendekatan pembelajaran kontekstual dengan media VCD. Penggunaan VCD sebagai media pembelajaran dapat meningkatkan hasil belajar yang signifikan. ${ }^{10}$ Penelitian lain sejenis yang menunjukkan bahwa penggunaan VCD yang cukup efektif se- bagai media pembelajaran atau penyuluhan adalah penelitian pemanfaatan media VCD pembelajaran matematika subpokok pengelolaan data untuk meningkatkan hasil belajar siswa kelas VI di Sekolah Dasar Nurul Ulum Surabaya. Hasil penelitian menunjukan bahwa pembelajaran dengan memanfaatkan media VCD dapat meningkatkan hasil belajar siswa. ${ }^{11}$ Hal tersebut juga sesuai dengan pendapat Colletti dalam Soekartawi, ${ }^{5}$ yang menyebutkan bahwa daya serap terhadap informasi yang diberikan dengan media VCD sekitar 75\%. Begitu pula dengan penggunaan leaflet sebagai media penyuluhan yang efektif dalam meningkatkan pengetahuan responden perlakuan sesuai dengan hasil penelitian $\mathrm{O}$, Neil, et $a l, 12$ yang membuktikan bahwa tanya jawab dan media leaflet dapat meningkatkan pengetahuan.

Pengaruh metode penggunaan VCD dan leaflet terhadap peningkatan rerata skor pengetahuan pencegahan kecelakaan sepeda motor pada responden kelompok perlakuan lebih tinggi dari pada peningkatan pengetahuan pencegahan kecelakaan pada responden kontrol (Tabel 3). Hasil tersebut menunjukan bahwa pada responden kelompok kontrol juga terjadi peningkatan pengetahuan tetapi sangat sedikit dan pada responden kelompok intervensi peningkatannya juga tidak tinggi sekali, tetapi perbedaannya secara statistik cukup bermakna. Beberapa hal yang mungkin menjadi hambatan dalam peningkatan pengetahuan responden pada kelompok yang diinterven- 
si adalah ruangan tempat penyuluhan yang kurang nyaman mungkin memengaruhi proses penerimaan pesan, frekuensi penyuluhan yang kurang banyak sehingga memengaruhi penyerapan materi penyuluhan dan terdapat responden yang tidak memutar lagi CD-nya di rumah atau ditempat lain meskipun telah dianjurkan, sebelum post test.

Terjadi peningkatan skor sikap terhadap pencegahan kecelakaan lalu lintas pada responden perlakuan secara bermakna tetapi tidak terjadi pada responden kontrol (Tabel 2). Peningkatan skor sikap mungkin terjadi karena adanya peningkatan pengetahuan pada kelompok perlakuan akibat intervensi. Hal tersebut sesuai dengan pendapat Notoatmodjo, 13 yang menyatakan bahwa sikap yang utuh ditentukan oleh pengetahuan, pikiran, keyakinan, dan emosi. Dengan demikian, dapat disimpulkan bahwa pemutaran VCD dan pemberian leaflet dapat meningkatkan sikap pengendara sepeda motor terhadap pencegahan kecelakaan lalu lintas sepeda motor.

Tidak terdapat perbedaan yang bermakna antara peningkatan skor sikap pada kelompok intervensi dengan kelompok kontrol (Tabel 3). Hal tersebut terjadi karena kenaikan skor sikap pada kelompok perlakukan hanya kecil. Kecilnya kenaikan skor sikap tersebut kemungkinan disebabkan oleh karena materi atau proses penyuluhan baru menyentuh pada sikap tingkat menerima (receiving) belum sampai pada tingkat merespons (responding). Hal tersebut sesuai dengan teori dari Notoatmodjo, ${ }^{14}$ yang mengemukakan bahwa sikap terdiri dari beberapa tingkatan yaitu menerima, merespons, menghargai, bertanggung jawab. Namun, dari hasil penelitian tentang pengaruh media ceramah, leaflet, dan VCD dalam pencegahan gangguan akibat kekurangan Iodium menunjukan bahwa penggunaan media leaflet dan VCD dapat meningkatkan pengetahuan, sikap dan perilaku pencegahan gangguan akibat kekurangan iodium. 15

Terjadi peningkatan skor perilaku tentang pencegahan kecelakaan lalu lintas pada responden kelompok kontrol secara bermakna (Tabel 2). Peningkatan skor perilaku pada kelompok responden kontrol mungkin disebabkan oleh adanya mobilitas yang tinggi dari siswa sehingga mereka banyak terpapar informasi tentang pencegahan kecelakaan lalu lintas dari sumber lain, sering adanya operasi penindakan pelanggaran lalu lintas, banyaknya informasi kejadian kecelakaan lalu lintas yang ditayangkan di TV menyadarkan mereka perlunya berperilaku yang tidak berisiko terjadinya kecelakaan lalu lintas, kemungkinan adanya kontaminasi informasi tentang pencegahan kecelakaan sepeda motor dari siswa SLTA kelompok perlakuan ke siswa SLTA kelompok kontrol, meskipun keduanya terpisah dengan jarak lebih kurang 8 kilometer. Hal tersebut terjadi mungkin karena pada saat responden dari kelompok perlakuan memutar VCD yang diberi dari peneliti, di rumahnya atau di tem- pat lain terdapat responden dari kelompok kontrol yang ikut menonton.

Kelompok responden yang di intervensi dengan media VCD dan leaflet menunjukan tidak ada perbedaan peningkatan yang bermakna antara skor perilaku pencegahan kecelakaan lalu lintas responden dari kelompok yang diintervensi dengan responden dari kelompok kontrol (Tabel 3). Artinya, pemutaran VCD dan pemberian leaflet tidak efektif untuk meningkatkan perilaku siswa dalam pencegahan kecelakaan sepeda motor. Hal tersebut berbeda dengan penelitian sejenis yang berjudul "Pemanfaatan Media VCD Dongeng Dancow Kisah Sebuah Guling Kecil untuk Meningkatkan Kemampuan Bercerita Siswa Kelas 5 pada Mata Pelajaran Bahasa Indonesia di SDN Slempit 2 Kedamean Gresik". Hasil penelitian tersebut menunjukan bahwa pembelajaran dengan memanfaatkan media VCD dongeng dancow dapat meningkatkan kemampuan bercerita siswa kelas V SDN Slempit 2 Kedamean. ${ }^{16}$ Penelitian oleh Ali, ${ }^{17}$ tentang Penggunaan Media VCD pada Senam Lantai Siswa SLTP di Jambi oleh Muhammad Ali menunjukan bahwa latihan menggunakan media VCD dapat meningkatkan hasil belajar head stand siswa sebesar 2,6 poin. Dengan demikian, menurut hasil penelitian tersebut penggunaan VCD sebagai media komunikasi dapat efektif untuk meningkatkan perilaku.

Wawancara terhadap responden yang mendapat penyuluhan dengan VCD dan leaflet tentang pencegahan kecelakaan sepeda motor, menunjukan bahwa VCD dan leaflet menarik dan komunikatif. Hal tersebut sesuai dengan pendapat Laura yang menyatakan bahwa video sebagai media instruksional dapat menggugah perasaan dan menarik minat dengan tujuan terjadi perubahan perilaku. ${ }^{18}$ Di samping itu, Notoatmodjo juga berpendapat bahwa keunggulan dari VCD sebagai media penyuluhan antara lain lebih mudah dipahami, lebih menarik, dapat bertatap muka, mengikut sertakan seluruh panca indera, penyajian dapat dikendalikan dan jangkauannya relatif besar. ${ }^{13}$

Penelitian tentang Penggunaan Bahan Ajar Leaflet terhadap Hasil Belajar Siswa, yang ditulis oleh Endah Tri Septiani menunjukan bahwa pembelajaran menggunakan media leaflet berpengaruh signifikan terhadap peningkatan hasil belajar siswa pada materi sistem gerak manusia. ${ }^{19}$ Dari beberapa penelitian sejenis seperti tersebut diatas semuanya menunjukan hasil bahwa penggunaan leaflet sebagai media komunikasi baik dalam kegiatan penyuluhan maupun pembelajaran cukup efektif. Penelitian lainnya mengemukakan bahwa tidak ada perbedaan yang signifikan peningkatan perilaku antara yang di intervensi dengan media Audio Visual dibandingkan dengan yang di intervensi menggunakan leaflet. ${ }^{20}$ Dari beberapa hasil penelitian tentang penggunaan VCD maupun leaflet, dapat disimpulkan bahwa kedua media komunikasi tersebut efektif untuk meningkatkan penge- 
tahuan, sikap dan perilaku sasaran.

\section{Kesimpulan}

VCD dan leaflet dapat digunakan sebagai media intervensi untuk meningkatkan pengetahuan, sikap, dan perilaku pencegahan kecelakaan lalu lintas sepeda motor yang efektif bagi siswa SLTA di Kota Bekasi. Hasil evaluasi terhadap siswa yang diintervensi menunjukan sebagian besar dari mereka menyatakan bahwa substansi media VCD dan leaflet, menarik dan komunikatif serta dapat meningkatkan sikap dan perilaku pencegahan kecelakaan sepeda motor. Berdasarkan hal tersebut, disarankan agar pihak terkait seperti Kementerian Pendidikan Nasional dan Kementerian Kesehatan serta POLRI bekerja sama melakukan penyuluhan pencegahan kecelakaan sepeda motor kepada masyarakat khusus siswa SLTA dengan menggunakan media VCD dan leaflet.

\section{Ucapan Terima Kasih}

Terima kasih kami sampaikan kepada Kepala Pusat Penelitian Biomedis dan Farmasi yang telah memberi kesempatan sehingga terlaksananya penelitian ini. Ucapan terima kasih kami sampaikan pula kepada Kepala dan staf guru SMA Negeri I, SMA Negeri VIII dan Kepala SMK Negeri I serta SMK Negeri III Kota Bekasi.

\section{Daftar Pustaka}

1. Kementerian Perhubungan Republik Indonesia.Undang-Undang Republik Indonesia Nomor 22 Tahun 2009 tentang lalu lintas dan angkutan jalan. Jakarta: Sekretariat Negara Republik Indonesia; 2010.

2. Sukarmin Y. Pendidikan keselamatan lalu lintas untuk anak sekolah dasar. WUNY Majalah Ilmiah Populer. 2009; 28 (1): 13-24.

3. Yahya MN. Keselamatan lalu lintas: kesehatan masyarakat yang Terabaikan. Kompas. 2005; 26 (9).

4. Supardi S, Sampurno OD, Notosiswoyo M. Pengaruh metode ceramah dan media leaflet terhadap perilaku pengobatan sendiri yang sesuai dengan aturan. Buletin Penelitian Kesehatan. 2002; 30 (3): 128-38.

5. Soekartawi. Meningkatkan efektivitas belajar. Jakarta: Dunia Pustaka Jaya; 1995.

6. Majid A. Perencanaan pembelajaran. Bandung: Remaja Rosdakarya; 2006

7. Makie IC, Wortington HV, Hopson P. An Investigation into sugar containing and sugar free over the counter medicine stocked and recommended by pharmacist in the North Western Region of England. British Dental Journal. 1993; 7 (3): 93-8

8. Mantra IB. Strategi penyuluhan Kesehatan. Jakarta: Pusat Penyuluhan Kesehatan Masyarakat Departemen Kesehatan RI; 1997.
9. Garnadi A. Penggunaan visual aid dalam penyuluhan pertanian. Jakarta: Direktorat Penyuluhan Pertanian; 1971.

10. Atno. Meningkatkan hasil belajar sejarah siswa melalui pendekatan pembelajaran kontekstual dengan media VCD pembelajaran. Paramita Jurnal Sejarah dan Pembelajaran Sejarah [online]. 2011 Oktober [diakses tanggal 5 Januari 2014]; 20 (1): 92-104. Diunduh dalam: http://journal.unnes.ac.id/nju/index.php/paramita/article/view/1091/1001

11. Novaliyanto HR, Sulistiowati. Pemanfaatan media VCD pembelajaran matematika subpokok pengelolaan data untuk meningkatkan hasil belajar siswa Kelas VI di Sekolah Dasar Nurul Ulum Surabaya. Jurnal Mahasiswa Teknologi Pendidikan [online]. 2014 (Diakses tanggal 5 Januari 2014); 2 (1). Diunduh dalam: http://ejournal.unesa.ac.id

12. O Neil P, Humphris GM, Field EA. The use of an information leaflet for patients undergoing wisdom tooth removal. Journal Oral Maxilofac Surgery. 1996; 34 (4) : 331-4.

14. Notoatmodjo S. Promosi kesehatan teori dan aplikasi. Jakarta: Rineka Cipta; 2005.

15. Notoatmodjo S. Pendidikan dan perilaku kesehatan. Jakarta: PT Rineka Cipta; 2003.

16. Metekohy FA, Sudargo T, Dewi FST. Pengaruh media ceramah, leaflet dan VCD dalam pencegahan gangguan akibat kekurangan yodium. Berita Kedokteran Masyarakat [online]. 2004 [diakses tanggal 20 Januari 2014]; 20 (3). Diunduh dalam: http://jurnal.ugm.ac.id/bkm/article/view/3699

17. Subeki F. Pemanfaatan media VCD dongeng Dancow kisah sebuah guling kecil untuk meningkatkan kemampuan bercerita siswa kelas $\mathrm{V}$ pada mata pelajaran Bahasa Indonesia di SDN Slempit 2 Kedamean Gresik. Jurnal Mahasiswa Teknologi Pendidikan [online]. 2013 [diakses tanggal 20 Januari 2014]; 1 (2). Availabel from: http://ejournal.unesa.ac.id/index.php/jmtp/article/view/2497

18. Ali M. Penggunaan media VCD pada senam lantai siswa SLTP di Jambi. Media Ilmu Keolahragaan Indonesia [online]. 2012 [diakses tanggal 20 Januari 2014]; 1 (1). Diunduh dalam: http://journal.unnes.ac.id/nju/index.php/miki/article/view/2549

19. Bix L. The elements of text and message design and their impact on message legibility. Journal of Design Communication. 2002; Spring (4).

20. Septiani ET, Jalmo T, Yolida B. Penggunaan bahan ajar leaflet terhadap hasil belajar siswa. Jurnal Bioterdik [online]. 2014 [diakses tanggal 4 Januari 2014]; 2 (4). Diunduh dalam: ejurnal fkip. unila .ac.id/index.php /JBT/article .

21. Hermaningsih S, Nargis. Penggunaan media bantu audio visual dan leaflet terhadap perubahan perilaku perawatan diri pra remaja di sekolah menengah pertama di Kecamatan Buah Batu Bandung. E Journal Stikes Ayani [online]. 2009 [Diakses tanggal 5 Januari 2014]. Diunduh dalam: http://www.stikesayani.ac.id/publikasi/e-journal/files/ 2010/201008/201008-004.pdf. 